\title{
Guerra justa insuficiente: a ideia da paz justa na construção da paz pós-guerra no cristianismo
}

Insufficient just war: the idea of a just peace in post-conflict peacebuilding in Christianity

Guerra justa insuficiente: la idea de una paz justa en la construcción de la paz posguerra en el cristianismo

Joyce Kelly Costa Silva ${ }^{1}$

DOI: $10.5752 /$ P.1809-6182.2019v13n3p34

Recebido em: 30 de junho de 2019 Aceito em: 01 de dezembro de 2019

\begin{abstract}
Resumo
A "paz justa" enfatiza a reconciliação e a justiça como paz. O objetivo do artigo é discutir como essa abordagem fornece uma alternativa à antiga tradiçáo da guerra justa na construção da paz pós-conflito no cristianismo.

Palavras chave: Religiāo. Paz. Cristianismo.

Abstract

A peace "just" emphasizes reconciliation and justice as peace. The purpose of the article is to discuss how this approach provides an alternative to the ancient tradition of just war in post-conflict peacebuilding in Christianity.

Keywords: Religion. Peace. Christianity.

\section{Resumen}

La paz justa"enfatiza la reconciliación y la justicia como paz. El objetivo del artículo es discutir cómo este enfoque proporciona una alternativa a la antigua tradición de la guerra justa en la construcción de la paz post-conflicto en el cristianismo.

Palabras clave: Religión. Paz. Cristianismo.
\end{abstract}

\footnotetext{
1 Mestra em Relaçóes Internacionais pela Universidade Estadual da Paraíba (2019), Bacharela em Relaçóes Internacionais pela Universidade Federal da Paraíba (2016) e Membra do Grupo de Estudos em Política, Relaçôes Internacionais e Religião (GEPRIR/ UEPB). ORCID: 0000-0002-0698-8342.
} 


\section{Introdução}

Os eventos do 11 de setembro e, mais ainda, as reaçóes ao 11 de setembro, convenceram o mundo de que a religião é a única ou a principal causa dos conflitos internacionais. De fato, o papel da religiáo é especialmente evidente quando invocado para justificar atos de violência, como os atentados suicidas, e as execuçóes ritualizadas de tais atos (OMER, 2010). Todavia, muitas vezes as interconexóes entre religião e violência desconsideram que da mesma forma que a religiáo é um fator importante na dinâmica do conflito, ela pode desempenhar (por meio de líderes religiosos e leigos) uma função na construção da paz (SMOCK, 2006). Certamente, existem inúmeros exemplos de violência religiosa em todo o mundo. Mas, afirmar que a religião é inerentemente violenta é ignorar que a paz é um dos principais fundamentos das principais religiôes do mundo.

A contribuição que a religiáo pode dar para a paz - como o outro lado da religião no conflito - está apenas começando a ser explorado e explicado. O surgimento desse novo campo de estudos chamado de "construção da paz religiosa" 2 tem como pano de fundo a revisão de antigos paradigmas, tais como: a guerra justa, a guerra santa, e o pacifismo. Esses paradigmas de forte raiz religiosa têm sido por séculos os principais meios em que a religião se insere nos debates sobre violência, conflito, guerra e paz (HERTOG, 2010). Na ética cristâ, o pacifismo representa uma atitude de rejeição à guerra, a

\footnotetext{
2 A prática e a utilização desse termo envolve tanto o diálogo inter-religioso, pelos quais indivíduos religiosos discutem o papel da religião entre as naçôes, quanto à descrição do trabalho de pacificadores cuja motivação das açóes em favor de vítimas e a implementação da paz e da justiça derivam de uma compreensão particular advinda de uma tradição religiosa (OMER, 2010).
}

guerra justa está associada à participação qualificada do cristão no serviço militar, já a guerra santa cristã representada pelas Cruzadas, está associada ao domínio da Igreja sobre o mundo (BAINTON, 2008).

A paz justa representa um importante ponto de virada na forma de lidar com a guerra no pensamento cristão. Além disso, esse paradigma questiona a tradição da guerra justa justamente como aquela que embora seja importante na limitação e/ou regulação moral da violência não contempla as questôes referentes ao pós-guerra ou a construção de uma paz sustentável (LOVE, 2018). Considerando que a grande maioria dos conflitos contemporâneos envolve uma série de razóes, tanto tangíveis quanto intangíveis, a religiáo pode ser uma variável decisiva, capaz de exercer um papel construtivo, como mediadora e promotora da reconciliação entre as partes (BERCOVITCH; KADAYIFCI-ORELLANA, 2009). Segundo Matyok e Flaherty (2015), não é possível ignorar a presença da religiáo na vida das pessoas. Bilhôes de pessoas moldam suas vidas a partir de crenças religiosas. Por isso, a construção de respostas multidisciplinares ao conflito, não pode ignorar a presença da religiáo (MATYOK, FLAHERTY, 2015). Logo, as discussóes a respeito da prática da abordagem da "paz justa" é uma oportunidade de demonstrar a capacidade reconciliatória do cristianismo no cenário internacional. ${ }^{3}$

Diante disso, o presente artigo tem como objetivo apresentar a nova abordagem da paz

\footnotetext{
3 Este artigo buscou abordar o cristianismo de forma geral, fundamentado nos ensinamentos de Jesus Cristo a respeito do conceito de paz justa. Todavia, é provável que em cada uma das vertentes do cristianismo ("catolicismos" e "protestantismos" - em referência às várias subdivisões) existam distinçôes sobre o significado e a aplicação da paz justa.
} 
justa como um contraponto à guerra justa na construção da paz pós-conflito no pensamento cristão. A guerra justa, apesar de contribuir para as discussóes sobre os limites para entrar em um conflito (jus ad bellum) e para conduzi-lo (jus in bello), provou ser suscetível a abusos políticos, além de conter um número de deficiências conceituais (HOPPE, 2007). Tendo em vista o "retorno" da religião às Relaçôes Internacionais (RI), parte-se aqui do pressuposto de que há uma influência dessa variável nas açôes dos indivíduos e que essas açôes podem favorecer a construção da paz em sociedades no pós-conflito.

\section{A tradição cristã da guerra justa}

A tradição da guerra justa surgiu como uma proposta de regulação dos conflitos por meio da ética. Ao longo da história humana, as sociedades passaram a considerar a importância da ética na guerra. Em quase praticamente todas as grandes civilizaçóes do mundo, dos antigos egípcios aos astecas, da Babilônia à Índia, da China à Europa antiga e contemporânea, praticamente todos defendem características e crenças fixas sobre quais são as razões permitidas para ir à guerra e quais os meios aceitáveis para lutá-la. Da mesma forma, em quase todos os principais documentos religiosos há alguma ponderação sobre a moralização da guerra, a exemplo da Bíblia cristã, do Bhagavad Gita hindu, do Tao-te-ching do Taoísmo e do Alcorão do Islá (OREND, 2013).

No cristianismo, a determinação básica é pacifista, derivada dos ensinamentos de Jesus Cristo. Jesus declarou: "Felizes os que promovem a paz" (BÍBLIA, 2016, p. 1249). Portanto, o cristáo deve trabalhar como um construtor da paz. Os primeiros cristãos eram pacifistas e rejeitavam qualquer participação no serviço militar. Segundo Bell (2005), existem pelo menos duas razóes que são tipicamente citadas para explicar essa posição. A primeira é que os cristãos primitivos seguiram os ensinamentos e os exemplos de Jesus Cristo e foram opostos ao derramamento de sangue e à violência. Esse é um argumento bastante discutido, mas mesmo para os teólogos defensores da guerra justa, como Agostinho, há o reconhecimento de que os cristãos primitivos eram mais pacíficos. A segunda razão refere-se ao caráter idólatra que o serviço militar tinha dentro de Roma. Para um cristão servir ao exército era preciso jurar lealdade e devoção ao Imperador (BELL, 2005).

Um dos primeiros filósofos cristãos a refletir sobre a guerra foi Agostinho (354-430) durante o governo de Constantino. Influenciado por filósofos romanos, ele ensinou que a guerra limitada poderia ser um meio legítimo de defender o Império. A guerra era um mal, mas poderia ser considerada justa quando travada em prol de propósitos defensivos, por meio de uma autoridade legítima, com intenções corretas e com dano mínimo. Ao defenderem a paz de Roma (pax romana), Agostinho argumentava que os cristãos estavam servindo a Deus e protegendo a pureza do cristianismo contra as heresias dos povos bárbaros (DUFFEY, 2015). Para Agostinho a presença dos bárbaros representava uma ameaça à unidade e à pureza doutrinária da Igreja cristá, ao passo que Roma representava o lugar de proteção para os cristãos, a qual, portanto, eles deveriam defender contra essa ameaça. Assim, ao contrário do pacifismo, a participação dos cristáos no serviço militar era moralmente possível diante de uma realidade bastante problemática e que causava sofrimento enorme nas pessoas (AGOSTINHO, 1996). 
Apesar de a guerra justa ser uma importante tradição no pensamento sobre a ética na guerra, ao longo dos anos essa perspectiva vem recebendo algumas críticas. De acordo com Bartoli (2004), a tentativa cristá de usar o poder militar e político durante o governo de Constantino eram no mínimo ambivalentes, pois, por um lado, inaugurou um novo período na história da Europa, por outro lado, possibilitou intervençóes violentas desastrosas como as Cruzadas (BARTOLI, 2004). Scott Appleby (2000, p. 34), diz que: "a existência da tradição moral da guerra justa no cristianismo avança nos argumentos sobre o uso apropriado da força, mas nunca a resolve”. Para o autor, a ambivalência e o próprio pluralismo existente dentro das tradiçóes religiosas estimulam o raciocínio situacional e a liderança pragmática (APPLEBY, 2000). Para Thomas Hoppe (2007), embora a tradição da guerra justa condene a violência e coloque parâmetros para a limitação da violência indiscriminada por parte do Estado, a partir do momento que ela estabelece critérios morais que tornam a violência justificada "como um mal menor", estas condiçôes ficam sujeitas a interpretaçáo, e inerentemente correm o risco de serem mal utilizadas (HOPPE, 2007).

De acordo com Selengut (2003), durante a Idade Média, a doutrina da guerra justa funcionou eficazmente como uma "guerra santa" para o cristianismo. O cristianismo como religiāo aceita dentro do Império Romano teve que proteger suas doutrinas de uma possível "contaminação teológica”. Logo, o "justo” uso da força foi entendido como forma de preservar a fé cristã genuína. Para o autor, a forma universalista defendida pela fé cristã destinada a oferecer à única possibilidade de salvação para toda a humanidade fez com que as guerras em nome da religiáo fossem justificadas (SELENGUT, 2003, p. 26). Assim, como aconteceu na guerra do Afeganistão (2001) e na guerra do Iraque (2003), os princípios da guerra justa e os valores ditos "cristãos" foram usados para fazer com que as pessoas acreditassem que essas guerras eram necessárias e "boas". De acordo com Fiala (2008), existe uma romantização em torno da ideia de guerra justa que náo permite enxergar a face brutal, caótica e horrível de uma guerra (FIALA, 2008).

Diante dessas críticas, é possível considerar a existência de falhas na abordagem da guerra justa. Além disso, como visto, o argumento da guerra justa cristá pode ser usado como motivaçáo ou justificativa para o uso indiscriminado da violência. $O$ fato é que, tanto o pacifismo cristáo quanto a guerra justa cristá se desenvolveram ao longo da história e buscaram à sua maneira responder às mudanças no cenário político. Nenhuma das posições representa um sistema fixo de afirmaçôes teológicas ou éticas. Ambos foram sujeitos a frequentes deturpaçóes e mal usos. No entanto, muitas vezes a ênfase na religião como fonte de conflito, retirou a força da religião na construção da paz. Assim, em decorrência das mudanças no cenário internacional (principalmente após as Guerras Mundiais) ${ }^{4}$ e dadas às limitaçóes da guerra justa, várias igrejas começaram a discutir a respeito de uma nova abordagem que estivesse em conformidade com os ensinamentos de Jesus Cristo e que tivesse o compromisso para a paz e não para a guerra. Essas igrejas desen-

\footnotetext{
4 Um dos aspectos fundamentais dessa mudança é com relação ao caráter dos conflitos. Antes da Guerra Fria os conflitos eram marcados por disputas ideológicas entre os Estados. Com o declínio do confronto Norte-Sul, os conflitos passam a ocorrer dentro dos Estados e na maioria das vezes derivam de confrontos de identidade comunitária com base na raça, etnia, nacionalidade ou religiáo.
} 
volveram um novo paradigma que incorpora a mudança fundamental na prática ética e amplia a estrutura de análise e critérios de ação para a Igreja Cristá no cenário internacional. Esse novo paradigma é a paz justa, como será visto a seguir.

\section{A paz justa e a construção da paz no cristianismo}

Desde o final da Segunda Guerra Mundial têm surgido dentro da tradição cristã abordagens referentes à construção da paz não-violenta (APPLEBY, 2004). A paz justa está inserida dentro dessa escola de pensamento. Historicamente, o movimento pela paz justa surgiu na Igreja Unida de Cristo (United Church of Christ, UCC) em 1981 quando, no Sínodo Geral um delegado trouxe uma resolução convocando a Igreja a tornar-se uma "igreja da paz" (ligada ao movimento pacifista). A resoluçáo foi aprovada, mas ficou claro que era preciso desenvolver essa abordagem. Sendo assim, em 1983 um grupo de teólogos e estudiosos se reuniu para criar fundamentos para essa abordagem, e em 1986, membros desse grupo criaram um livro, editado por Susan Thistlethwaite intitulado "A Just Peace Church" que se tornou uma fonte primária para a abordagem da paz justa (UCC, 2015).

Ao longo dos anos a ideia de paz justa foi se aperfeiçoando e não ficou restrita somente a Igreja da Paz. Em 2011 a Convocatória Ecumênica Internacional pela Paz (IEPC) do Conselho Mundial de Igrejas (CMI) produziu dois documentos seminais: "Um chamado Ecumênico à paz justa" e a "Companhia da paz justa". O primeiro documento declarou que a perspectiva e o pensamento da guerra justa são obsoletos. O segundo traz uma extensa orientação sobre a implementação da teologia da paz justa. Em ambos os documentos há o argumento de que a mensagem de Cristo convida os cristãos a comprometer-se com o "caminho da paz justa”. Esse caminho é trilhado por meios de resistência não-violenta, de transformação de conflitos e de promoção da reconciliação (BERGER, 2016).

A paz justa cristã traduz a visão bíblica da paz em termos contemporâneos, a partir da relação interdependente entre justiça e paz. A tradução hebraica para paz, o shalom é geralmente traduzido com "completude, solidez, bem-estar e paz", mas também liga a paz a conceitos como: justiça (mishpat), retidão (tsedeq, tsedeqah) compaixão (hesed) e veracidade (emet) (CHURCHES, 2011). De acordo com Smyth (2008, p. 348), “onde há injustiça ou violência contra os fracos, a paz de Deus é destinada ao exílio. A paz traz justiça, e é essa justiça que assegura que o shalom prevaleça sobre os interesses humanos e falsa paz". Na prática, pode haver divergências entre os imperativos da justiça e a necessidade da paz, no entanto, é dentro desse desacordo que a reconciliação é trabalhada para estabelecer a paz justa (SMYTH, 2008). De maneira geral, a paz justa significa a prática da justiça social definida em termos de reconciliação. Em outras palavras, a justiça se manifesta na reconciliação, que é o meio para alcançar o fim que é a paz justa. ${ }^{5}$

As discussóes sobre a paz justa no cristianismo dizem respeito à revisão de paradigmas tradicionais ocorridas dentro do novo campo de estudo da "construção da paz religiosa", que enfatiza que da mesma forma que a religião pode incentivar os conflitos ela pode ajudar a resolvê-los e construir a paz (APPLEBY, 2000).

\footnotetext{
5 Embora contenha componentes retributivos, a justiça bíblica é fundamentalmente sobre restauração, reparação e reconciliação. Para saber mais: MARSHALL, Chris. Divine justice as restorative justice. Center for Christian Ethics, p. 11-19, 2012.
} 
Segundo Omer (2010), a religiáo pode ser um fator importante na construção da paz em pelo menos três níveis: primeiro, ela motiva e inspira os indivíduos a agirem de determinada maneira que promova a paz e a não-violência. Segundo, as infraestruturas institucionais podem ser importantes espaços de mediação e cooperação entre redes e organizaçóes não-governamentais. Da mesma forma, o prestígio dos líderes religiosos e atores leigos podem conferir legitimidade a processos políticos e institucionais de reconciliação e cura pós-conflito. Terceiro, a religião e a tradição oferecem amplos recursos para reinterpretação de definiçóes etno-religiosas de nacionalidade que resultam em práticas estatais excludentes e discriminatórias e agressóes não-estatais (OMER, 2010).

Nessa perspectiva, pressupondo os ensinamentos da paz justa, indivíduos, comunidades e instituiçôes religiosas cristãs estão cada vez mais atuantes nas tentativas de acabar com os conflitos violentos e construir a paz em diversas partes do mundo. Apesar de esse fenômeno ter ganhado maior atenção após a Guerra Fria, ele não é algo novo. Os exemplos incluem a: mediação realizada pelos Quakers e financiada pela fundação Ford na Guerra Civil da Nigéria (1967-1970); os esforços dos Menonitas por meio do professor John Paul Lederach ${ }^{6}$ na Nicarágua na década de 1980; o trabalho do Conselho Mundial de Igrejas na mediação e cessação do conflito no Sudão em 1972; a mediação promovida pela comunidade leiga católica Sant'Egidio em Moçambique, funda-

6 Lederach é um dos teóricos responsáveis pelas discussôes sobre a construção da paz religiosa. Vale salientar que essas discussões ainda são iniciais e restritas à Universidade católica norte americana de Notre Dame. Fazem parte desse campo: Scott Appleby (2000), Atalia Omer (2010), Daniel Philpott (2010), entre outros. mental para por fim a guerra civil em 1992 (HAYNES, 2009).

$\mathrm{O}$ caso do Sudão chama a atenção pela promoção da reconciliação por meio do diálogo inter-religioso. Depois das negociaçôes de 1972 promovidas pelo Conselho Mundial de Igrejas terem alcançado sucesso ao encerrar a primeira guerra civil sudanesa, a dimensão religiosa do conflito no Sudão passou a ter destaque após a implantação da sharia (lei islâmica) em setembro de 1983 pelo presidente Numeiry sem qualquer consideração pelos não-muçulmanos da região. Historicamente, muçulmanos e cristãos conviviam pacificamente, contudo, após a implantação forçada da sharia houve um estranhamento entre eles. Todavia, isso foi essencial para que pessoas de diferentes religiôes se unissem em vez de se dividirem para buscarem soluçóes para que a paz fosse estabelecida no Sudão. O Conselho de Igrejas no Sudão do Sul tornou-se um espaço em que líderes cristãos e muçulmanos passaram a discutir soluçóes pacíficas para o Sudão (LOWILLA, 2006).

$\mathrm{O}$ que chama a atenção nesse caso é que ao mesmo tempo em que as açôes em prol da paz são efetuadas pelo Conselho Ecumênico de Igrejas no Sudão do Sul, a guerra geralmente tem sido interpretada como um conflito envolvendo o norte islâmico arabizado dominante, mais desenvolvido, contra o sul africano, menos desenvolvido e predominantemente cristão e animista (LOWILLA, 2006). No entanto, como explica Assefa (1990), seria simplista demais reduzir as guerras civis no Sudão baseada puramente nas diferenças religiosas. A divisão religiosa entre cristãos e muçulmanos se sobrepóem a divisóes profundas de raça, etnia e geografia. A esperança para o Sudão é que o diálogo possa abrir caminhos para a resolução do conflito e diminuição da violência 
(ASSEFA, 1990). Segundo Hayward (2012), em ambientes conflituosos em que existe alguma divisão religiosa, o diálogo inter-religioso é uma maneira de construir relacionamentos cooperativos. O diálogo inter-religioso é capaz de promover açôes transformadoras em prol da construçáo de uma paz justa após conflitos violentos (HAYWARD, 2012).

\section{Conclusão}

Scott Appleby (2000) chamou a atenção para a idéia da "ambivalência do sagrado", ao perceber que os ensinamentos, narrativas e reivindicaçóes religiosas têm sido predominantemente associados com os conflitos violentos em todo o mundo. Indiscutivelmente, as expressôes mais audíveis da religião é a associação dessa variável com a violência no âmbito político. Contudo, os ensinos, as autoridades religiosas e os indivíduos têm constituído um central, embora negligenciado, aspecto da prática de resolução de conflitos e construção da paz (APPLEBY, 2000).

Esse artigo buscou apresentar a nova abordagem da paz justa como um contraponto à tradição da guerra justa na construção da paz pós-conflito no cristianismo. A paz justa é uma evolução do conceito de paz no pensamento cristão. Na Bíblia, a palavra "paz" pode se referir à ausência de um conflito, mas também aponta para a presença de algo. A definição da paz como justiça que se manifesta na reconciliação pode ser sem dúvidas uma das grandes contribuiçôes teológicas para a construção da paz e, portanto, para uma percepção para o bem, do papel público da religiáo.

De fato, existem casos que mostram que os aspectos mais nobres da religiáo foram usados para facilitar a reconciliaçáo desafiando a percep- ção comum de que essa variável causa violência. No Sudão do Sul, o diálogo relacional é usado como plataforma para a reconciliação e mitigação das animosidades. É certo que isso tem sido mais uma exceção do que uma regra. No entanto, isso nos desafia a reconhecer o grande potencial inerente à religiáo para amenizar as paixóes destrutivas e se tornar um instrumento para a paz.

\section{Referências}

AGOSTINHO, Bispo De Hipona. A cidade de Deus. Lisboa: Fundaçãoo Calouste Gulbenkian. 1996.

APPLEBY, R. Scott. The Ambivalence of the Sacred: Religion, Violence, and Reconciliation. Lanham, MD: Rowman \& Littlefield. 2000

APPLEBY, R. Scott. Disciples of the Prince of Peace? Christian Resources for Nonviolent Peacebuilding. In: SM Heft, James. Beyond Violence: Religious Sources of Social Transformation in Judaism, Christianity, and Islam. New York: Fordham University Press, 2004. p. 113-144

ASSEFA, Hizkias. Religion in the Sudan: Exacerbating Conflict or Facilitating Reconciliation?. Bulletin of Peace Proposals, v. 21, n. 3, p. 255-262, 1990.

BAINTON, Roland H. Christian attitudes toward war and peace: a historical survey and critical re-evaluation. Abingdon: Wipf and Stock Publishers, 2008.

BARTOLI, Andrea. Christianity and peacebuilding. Religion and peacebuilding. In: COWARD, Harold; SMITH, Gordon S. (ed.). Religion and peacebuilding. Albany: SUNY Press, 2004. p. 147-166.

BELL, Daniel M. Just War as Christian Discipleship. Grand Rapids: Wipf and Stock, 2005.

BERGER, Rose Marie. No Longer Legitimating War: Christians and Just Peace. Nonviolence and Just Peace Conference 11-13, Roma, Italia, p. 39-54, abr. 2016.

BERCOVITCH, Jacob; KADAYIFCI-ORELLANA, Ayse. Religion and mediation: The role of faith-based actors in international conflict resolution. International Negotiation, v. 14, n. 1, p. 175-204, 2009.

BÍBLIA. Bíblia Sagrada Nova Versão Transformadora NVT. São Paulo: Mundo Cristáo, 2016.

CHURCHES, World Council Of. An Ecumenical Call to Just Peace, Geneva: WCC Publications. 2011.

DUFFEY, Michael K. Christianity From Peacemaking to Violence and Home Again. In: OMAR, Irfan A.; DUFFEY, Michael $\mathrm{K}$. (ed.). Peacemaking and the challenge of violence in world religions. Chichester: John Wiley \& Sons, 2015, p. 47-74. 
FIALA, Andrew. The just war myth: the moral illusions of war. New York: Rowman \& Littlefield, 2008.

HAYNES, Jeffrey. Conflict, conflict resolution and peace-building: the role of religion in Mozambique, Nigeria and Cambodia. Commonwealth \& Comparative Politics, v. 47, n. 1, p. 52-75, 2009,

HAYWARD, Susan. Religion and peacebuilding: reflections on current challenges and future prospects. Washington, DC: US Institute of Peace, 2012.

HERTOG, Katrien. The complex reality of religious peacebuilding: conceptual contributions and critical analysis. New York: Lexington Books, 2010.

HOPPE, Thomas. Just peace as leading perspective: towards the concept and task profile of an ethics of international politics. Studies in Christian Ethics, v. 20, n. 1, p. 68-76, 2007.

LOVE, Maryann Cusimano. Just Peace and Just War. Expositions, v. 12, n. 1, p. 60-71, 2018.

LOWILLA, Emmanuel. Intrafaith and interfaith dialogue in southern Sudan. In: SMOCK, David R. et al. Religious Contributions to Peacemaking: when Religion Brings Peace. Not War, Washington: United States Institute of Peace, Peaceworks, n. 55. p. 25-28, 2006.

MARSHALL, Chris. Divine justice as restorative justice. Center for Christian Ethics, p. 11-19, 2012.
MATYOK, Thomas; FLAHERTY, Maureen. Can People of Faith, and People in Peace and Conflict Studies, Work Together?. In: MATYÓK, Thomas et al. (ed.). Peace on Earth: the role of religion in peace and conflict studies. Maryland: Lexington Books, 2015.

OREND, Brian. The morality of war. Toronto: Broadview Press, 2013.

OMER, Atalia. Conflict and Peacebuilding. In: HECHT, Richard D.; BIONDO, Vincent F.. Religion and Everyday Life and Culture. Pennsylvania: Greenwood Publishing Group, Incorporated, 2010. p. 513-548.

PHILPOTT, Daniel; POWERS, Gerard. Strategies of Peace. New York: Oxford University Press, 2010.

SELENGUT, Charles. Sacred fury: understanding religious violence. Lanham: Rowman \& Littlefield, 2003.

SMOCK, David R. (ed.). Religious contributions to peacemaking: when religion brings peace, not war. Washington, DC: US Institute of Peace, 2006.

SMYTH, Geraldine. Brokenness, forgiveness, healing, and peace in Ireland. In: HELMICK, Raymond G.; PETERSEN, Rodney (ed.). Forgiveness \& Reconciliation: Public Policy \& Conflict Transformation. Pensilvânia: Templeton Foundation Press, 2008. p. 329-359.

UCC, United Church Of Christ. Just Peace Church Handbook. Washington, DC: Justice And Witness Ministries, 2015. 